\title{
(Auto)Biographical reflections on the contributions of William F. Loomis (1940-2016) to Dictyostelium biology
}

\author{
ADAM KUSPA ${ }^{*, 1}$ and GAD SHAULSKY*,2 \\ ${ }^{1}$ Verna and Marrs McLean Department of Biochemistry and Molecular Biology and \\ ${ }^{2}$ Department of Molecular and Human Genetics, Baylor College of Medicine, Houston, Texas, USA
}

\begin{abstract}
William Farnsworth Loomis studied the social amoeba Dictyostelium discoideum for more than fifty years as a professor of biology at the University of California, San Diego, USA. This biographical reflection describes Dr. Loomis' major scientific contributions to the field within a career arc that spanned the early days of molecular biology up to the present day where the acquisition of high-dimensional datasets drive research. Dr. Loomis explored the genetic control of social amoeba development, delineated mechanisms of cell differentiation, and significantly advanced genetic and genomic technology for the field. The details of Dr. Loomis' multifaceted career are drawn from his published work, from an autobiographical essay that he wrote near the end of his career and from extensive conversations between him and the two authors, many of which took place on the deck of his beachfront home in Del Mar, California.
\end{abstract}

KEY WORDS: genomics, differentiation, cell motility, amoeba, signaling

\section{Introduction}

William Farnsworth Loomis Jr. carried out cell and developmental biology research on Dictyostelium discoideum (referred to throughout as Dictyostelium) for over fifty years and provided insights into the genetic control of development, delineated mechanisms of cell differentiation, as well as significantly advancing genetic and genomic technologies for the field. Bill, as he was known in the field, published over 240 research articles, scholarly reviews and books on Dictyostelium. In this retrospective we provide a brief review of Bill's many accomplishments and relate our personal insights into how he achieved them. We draw heavily from Bill's own words by quoting from "My life with Dicty" posted in 2016 on dictyBase.org (Loomis 2016b). We made minor edits to the text [indicated by brackets] to improve clarity within the context of our commentary and we added references to Bill's papers. Our reflections are not intended to establish scientific priority regarding any particular discovery or concept. They are based on published work, what we have discussed with Bill directly, and Bill's own views of the field. Our conversations with Bill spanned thirty-seven years; when Adam Kuspa (Adam) was an undergraduate student in his laboratory (1979-1983) and later when he was a postdoctoral fellow (1989-1993), while Gad Shaulsky (Gadi) was a postdoctoral fellow (1992-1997), and continued after we both started our own laboratories at Baylor College of Medicine in Houston, Texas.

\section{Early influences}

Bill came from a long line of distinguished scientist-philanthropists dedicated to serving society and the greater good (Conant 2002). His great-great grandfather and great grandfather were nineteenth century physician-scientists who built sanitariums for tuberculosis patients in the USA. His grandfather, Alfred Lee Loomis, developed radar in a physics laboratory in his Tuxedo Park barn and then funded what became the "Rad Lab" at the Massachusetts Institute of Technology (MIT), where the high-power radar that was so instrumental in winning World War II was developed. It was here that Alfred conceptualized the long-range navigational system, LORAN, which was the first global positioning system that used microwaves reflected off the ionosphere to track planes and ships. Alfred also helped to fund the construction of Ernest Lawrence's 184-inch cyclotron at the Berkeley Radiation Laboratory and was one of the first to publish on electroencephalography. Bill's father, William Farnsworth Loomis Sr., "Farney" to his biochemist colleagues, was a physician and professor of Biochemistry at Brandeis University, who worked with Fritz Lippmann of ATP fame.

While working towards his biochemistry degree at Harvard, Bill

Abbreviations used in this paper: MIT, Massachusetts Institute of Technology; NTG, N-methyl-N'-nitro-N-nitrosoguanidine; REMI, restriction enzyme mediated integration; UCSD, University of California, San Diego.

\footnotetext{
*Address correspondence to: Adam Kuspa. Verna and Marrs McLean Department of Biochemistry and Molecular Biology, Baylor College of Medicine, Houston, Texas USA 77030. e-mail: akuspa@bcm.edu - (D) https://orcid.org/0000-0002-9156-149X or Gad Shaulsky. Department of Molecular and Human Genetics, Baylor College of Medicine, Houston, Texas USA 77030 e-mail: gadi@ bcm.edu - (iD) https://orcid.org/0000-0002-0532-0551
}

Submitted: 4 July, 2019. Accepted: 15 July, 2019. 


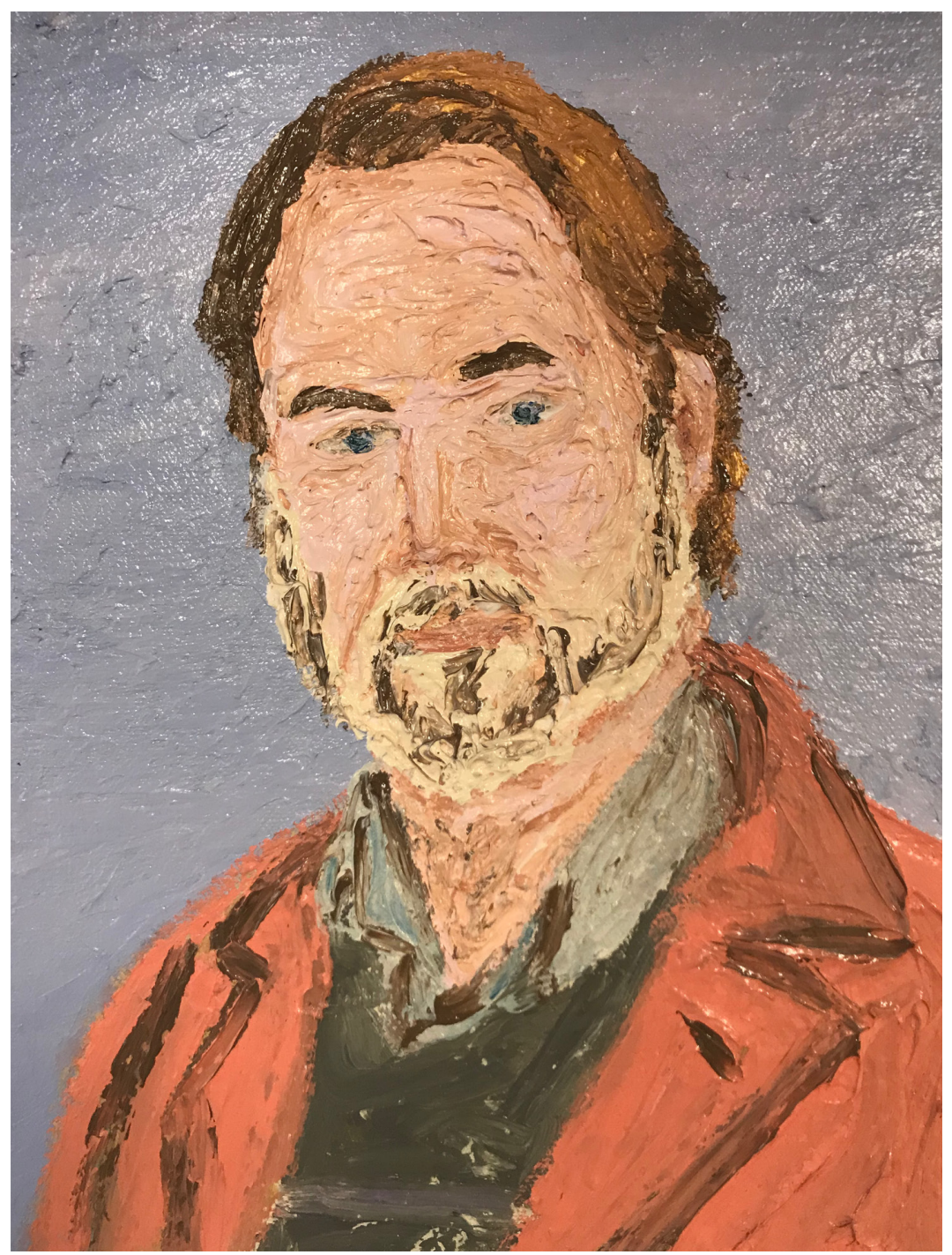

Fig. 1.William (Bill) Farnsworth Loomis (1940-2016). Oil on canvas by Alex Nguyen Vo. was that Bill met Maurice Sussman there and Maurice introduced Bill to Dictyostelium (Loomis 2016b). "One of the instructors was Maurice Sussman who made a lot of sense when he explained how developmental processes should be studied in their simplest form such as in the social amoeba Dictyostelium discoideum. After some interesting discussions, Sussman asked one of his graduate students, David Sonneborn, to show me how easy it was to collect growing Dictyostelium amoebae and initiate synchronous development. For the next 24 hours my attention was totally focused on the developing cells as they aggregated, formed slugs, and culminated into fruiting bodies. I was enamored but did not realize for several years that it would be a life long affair." Maurice introduced to Bill the concept that model organisms such as Dictyostelium could inform mechanistic studies in animals, but it took another ten years before he would be completely convinced.

The work of Francois Jacob and Jacques Monod on gene control in bacteria influenced Bill to consider genetics as a route to understanding development. "They had worked with the bacterium Escherichia coli, where they were able to use microbial genetics to generate and manipulate mutant genes, but they pointed out that similar mechanisms might account for the differentiation of cell types during embryogenesis. I was excited and convinced that they might be right, although it required a leap of faith to consider that 'All that is true of E. coli is true of elephants' as Monod had quipped. I accepted it and wanted to test it by applying detailed genetics to multicellular development. Back in the 60's, genetic techniques were limited to a few model systems. Dictyostelium was one of them."

It was the summer of 1961 that Bill spent in David Bonner's laboratory at the University of California at San Diego (UCSD) that convinced him that mastering microbial genetics would be a useful prerequisite for tackling animal development. "Dave was an unusual man and an exceptional scientist who worked on the tryptophan synthase gene in the bread mold Neurospora

was exposed to the exciting new science of molecular biology by interacting with luminaries in the field. "I majored in biochemistry and spent much of my time in the laboratory of Max Pappenheimer, who patiently took charge of my education. In his lab I worked on oxidative phosphorylation. I also got to talk with Jim Watson and Wally Gilbert who worked in their labs down the hall. They had ideas about $m R N A$ and DNA control that were far ahead of the text books." Bill also worked at Wood's Hole Marine Biology Station in the summer of 1960. In his spare time he sampled seawater and, in his first scientific publication, reported the constancy of carbon dioxide tension at various depths (Loomis and Loomis 1960). It was there that he also audited the Marine Biology Laboratory Embryology course. Though the embryology course at Woods Hole was well known for teaching about sea urchin development and chick limb morphogenesis, Dictyostelium development was also on the syllabus. While he was impressed with Zwilling and Saunders discoveries on the signaling involved in chick limb bud morphogenesis, he realized that the technology available at the time was too limiting to adequately test their models. Perhaps more consequential crassa. He showed how biochemical genetics could further define the 'one gene, one enzyme'hypothesis and provide surprises along the way. The best thing about being in the Bonner lab was being treated as their graduate student. Although I was still fascinated by embryogenesis, I thought that mastering microbial genetics first would make it much easier to confront multicellular organisms."

Bill's experience with Neurosporagenetics informed his decision to do his doctoral work with Boris Magasanik at MIT, where Bill genetically defined catabolite repression of lactose utilization as a distinct mechanism controlling the expression of $\beta$-galactosidase from the lacZ gene (Loomis and Magasanik 1967, 1966, 1965). "I wanted to see if catabolite repression could account for diauxic growth by regulating lacZ expression in a manner independent of the $i$ [lacl] gene. If we could show combinatorial control of the lac operon, it would present a much more versatile model for regulation Mixing and matching these independent control systems allows for a wide range of outputs. Throughout the time that I was getting proficient in genetically manipulating $\mathrm{E}$. coli I followed the literature of complex embryological processes than a simple on-off switch. 
on yeast and Dictyostelium."

Though intellectually prepared to study animal development after graduate school, Bill's options in the early 1960's were developmental systems that were mainly observational (chickens, frogs) or mainly genetic (Drosophila), while microbial systems such as Dictyostelium offered the potential to apply genetics, biochemistry and cell physiology towards an understanding multicellular development. Raquel and Maurice Sussman's laboratory at Brandeis University was one of the major Dictyostelium labs at the time and they were the only ones spearheading efforts to apply biochemical and genetic analyses to developmental physiology. "Maurice was always looking for the big breakthroughs that would affect how cellular physiology is understood. He chose to study Dictyostelium because it showed clean separation of growth and development and had the potential for microbial genetics." After deciding to work on multicellular development in Dictyostelium, the Sussman laboratory was the logical place for Bill to conduct his postdoctoral work. "[Sussman] had always been interested in how synthesis of new proteins directed cell differentiation and morphogenesis. UDP-galactose polysaccharide transferase was the first well-defined developmentally regulated protein of Dictyostelium (Sussman and Osborn 1964). Having a quantitative assay for this activity opened up many avenues for further exploration."

During his postdoctoral training Bill began two modes of experimentation into Dictyostelium that would influence the rest of his career; dissecting developmental regulatory pathways and genetic analyses. Bill began to explore the potential regulatory relationships between the expression of developmentally controlled enzymes and fruiting body morphogenesis (Loomis and Sussman 1966). He shared an office with John Ashworth beginning many years of fruitful collaboration. "Many of the experimental lines [John and I] talked about were never successful or did not come to a successful conclusion for many years, but that did not diminish the intellectual excitement of the moment. One dream that led almost immediately to a joint project was to show that specific genes were responsible for developmental morphogenesis. Keep in mind that this was at least 7 years before cloning techniques were worked out to isolate DNA regions in bacterial plasmids. Our experiments had to be indirect. Raquel and Maurice had recently shown that actinomycin $D$ blocked synthesis of all RNAs other than tRNAs in Dictyostelium. They also showed that it blocked accumulation of UDP-galactose polysaccharide transferase if added before the slug stage when the enzyme accumulated. We decided to add the drug at two-hour intervals throughout development and characterize the terminal structures for intercellular adhesiveness, stalk formation, spore formation and pigment accumulation. We took turns staying up all night as we carried out repeats of this experiment. The results clearly exposed the role of RNA synthesis on morphogenesis at different stages (Sussmanet al., 1967)." In retrospect, it is interesting to see how Bill grappled with the question of gene expression in relation to developmental regulatory events using relatively crude tools such as global transcriptional inhibitors, knowing that he would analyze the transcription of all genes with RNAseq about 40 years later (Rosengarten et al., 2015).

During this time Bill also came to internalize how useful genetic analyses could be in defining developmental events. "Together with his wife, Raquel, [Maurice] quickly developed techniques for isolating mutant strains that grew normally but showed aberrant morphogenesis. He found that when he mixed some of these strains together, they synergized; that is, they formed fruiting bodies when developed in mixed populations but not when incubated separately. Clearly, cells of these strains were communicating with each other. Kai [Yanagisawa] and I started thinking how to improve genetic techniques in Dictyostelium and soon focused on the choice of mutagen. I had used N-methyl-N'-nitro-N-nitrosoguanidine (NTG) extensively to mutate E. coli at MIT and brought some along with me to Brandeis. Kai and I found that NTG was a remarkably potent mutagen for Dictyostelium and proceeded to isolate a series of mutant strains. They were characterized by the developmental stages that they could reach before morphogenesis was arrested as well as by the developmental behavior of the marker enzyme that Maurice had discovered, UDP-galactose polysaccharide transferase. We found that mutants blocked before the stage when transferase normally accumulated failed to accumulate the activity while strains blocked at later steps accumulated transferase at the usual time to the usual level. Some of the strains that failed to make normal aggregates when incubated as pure populations formed fruiting bodies and accumulated transferase activity when incubated as mixed populations with each other. In other words, they synergized at both the morphological and the molecular level. This was the first time that cell-cell interaction among mutant strains was shown to regulate developmental gene expression (Yanagisawa et al., 1967)."

"Maurice was always stimulating to be with in the lab. He would sit down in the middle of any discussion and take over the conversation. He was full of ideas and opinions. He loved to be outrageous as well as brilliant and usually succeeded in both." After eight months in the Sussman lab, Maurice asked Bill when he was going to get a job. Maurice had taught Bill "everything that I had wanted coming to his lab", and it was time to hit the job market. Influenced by his positive experience in John Bonner's lab six years earlier, Bill sought out and was granted a job interview at UCSD in the fall of 1966. Bill gave a seminar on his graduate work on the regulation glucose/lactose diauxie in E. coliand in his chalk talk he "tried to outline how this style of thinking could be applied to more complicated problems in multicellular development." Bill accepted an assistant professorship at UCSD, and in early 1967 he set up his laboratory and remained there for 50 years. Note that Bill spent 16 months as a postdoctoral fellow and went on one job interview before starting his independent career in Dictyostelium research at the age of twenty-six. Clearly, the tempo and mode of science apprenticeship has changed greatly over the decades.

\section{Development in Dictyostelium}

Though Bill developed several projects in his laboratory in his first ten years at UCSD, he focused on the use of temporally regulated enzymes as markers for the progression of Dictyostelium development and, as we describe below, on developing genetic tools that would greatly aid the analyses. Bill investigated many aspects of Dictyostelium development, including slug phototaxis, cAMP/PKA signaling in development and in cell motility, cell differentiation, and the coupling of spore differentiation to terminal morphogenesis. The 1960's and 1970's were a time when "one protein, one professorship" was still the rule, but Bill was much too creative and energetic to focus on one thing. It is refreshing that there is room for scientists like Bill who follow their imagination without concern for what is "fundable" by governmental agencies 
or what work would pave the road to promotion and tenure. Bill taught us to follow this path as well.

This early period also inspired Bill to write a book; "Dictyostelium discoideum. A developmental system" (Loomis 1975). This remains an interesting reference work that focuses on the biology of Dictyostelium as a model system, just prior to the explosion of molecular genetic analyses would begin to provide mechanistic details. It also contains a wonderful collection of light and electron micrographs depicting cellular and developmental processes. This work was followed seven years later with a volume edited by Bill, "The development of Dictyostelium discoideum", that contained much more detailed information from experts in the field (Loomis 1982). It is also noteworthy that Bill and his administrative assistant Robin Cann assembled a complete bibliography of published work on Dictyostelium without the benefit of the Internet (Loomis and Cann 1982). One of us (Adam) remembers Robin trundling down to Bill's office inside the lab with reams of mainframe computer printouts from the UCSD biomedical library, and Bill grumbling as he edited the entire morass by hand over a period over many days.

\section{Development as a pathway}

Bill began with the enzyme defined in the Sussman lab, UDPgalactose polysaccharide transferase, as a marker for development. However, "[t]he assay for transferase was always cumbersome and I wondered if it could be replaced with an assay as easy as the one for $\beta$-galactosidase that I had used in my graduate work on the lac operon. All you had to do was lyse the cells and add a nitrophenol derivatized sugar as substrate. The bright yellow product could be seen with the naked eye and its rate of production quantitatively measured. I went to the catalogs of the chemical supply houses and ordered every nitrophenol derivatized substrate they had for sale. There were about a dozen. Within a few weeks I was able to test extracts of vegetative cells, aggregating cells, slug cells and culminating cells for activity in hydrolyzing these substrates. I found six enzyme activities that changed abruptly at one stage or another of development. They provide quantitative traits when there are no changes in visual phenotypes."By analyzing whether the enzyme markers accumulated normally or not during the course of development of the mutants blocked at different morphological stages, Bill and his colleagues were able to propose developmental regulatory pathways as a set of dependent sequences of events (Loomis et al., 1976, 1977).

"While we were fairly sure that the cells had to signal each other to progress through the dependent sequence, we did not know what the signals might be. A talented graduate student, Laura Grabel, developed an assay to purify a quorum sensor that triggered expression of the marker enzyme $\mathrm{N}$-acetylglucosaminidase (NAG). This early developmental enzyme required conditioned medium for expression in low-densitypopulations. Grabelmanaged to purify a low molecular weight, heat resistant component that was secreted by the cells and induced NAG (Grabel and Loomis 1978). Further purification was not possible due to the difficulty of the assay. However, many years later, Richard Gomer characterized a protein which he called CMF (conditioned medium factor) that he showed gave rise to peptides with the activity Grabel had described (Gomer et al., 1991)."

Though the models Bill proposed would be superseded with models based on molecular mechanisms over the ensuing few decades, these early descriptions established important concepts that could be generalized across the entire course of development. This was also of practical importance because it highlighted an important consideration for interpreting results of developmental genetic experiments; that of direct versus indirect effects. Later on, as cell biologists used mutants or in vitro methods to study chemotaxis during aggregation, they had to consider whether or not all of the chemotactic components were present because regulatory blocks at earlier developmental stages might preclude their accumulation.

After four years at UCSD Bill thought a sabbatical in Europe would be a good way to explore other developmental systems that might be better suited to his needs. (Spoiler alert: Bill did not change fields!) "Many people thought that Dictyostelium was so evolutionarily removed from mammals that it could not be useful as a model system for any aspect of human biology. The new data on chemotactic motility and transcriptional logic argued against that point of view and showed how certain aspects of development in Dictyostelium illuminated similar processes in more complex organisms. But it would always be an uphill effort to convince embryologists and members of the biomedical community that Dictyostelium studies were relevant. Perhaps it would be better to work directly with mammalian cells. Humans carry interesting mutations that turn up at clinics when they are disabled. However, you had to be part of the biomedical community to have access to these patients. On the other hand, mouse genetics was well developed with inbred lines and some interesting phenotypes. Heterozygous lines carrying embryonic lethal mutations could be bred such that a quarter of the embryos were homozygous mutants showing the desired trait. It wasn't efficient but it was possible. However, no one was systematically generating embryonic lethals in mice because it was so laborious and expensive. It would be many years before the techniques for manipulating embryonic stem cells to generate mutant mice would be developed. If you wanted to use mutational genetics in mammals in the 70's, you had to use established cell lines. I found that David Yaffe had generated a rat cell line at the Weizmann Institute in Israel that would grow exponentially as single cells and differentiate into multinucleated myotubes when they became confluent. Their differentiation was rapid, robust and easily monitored by visual inspection of the colonies. With a little more detective work in the library, I found that there was a lab in Paris that was working with Yaffe's L6 line of rat myoblasts. It was sounding better and better."

"After settling in Paris, I started work with the L6 cells. As soon as I was comfortable growing the cells, I killed large numbers with the mutagen NTG that I routinely used with Dictyostelium. A high proportion of the survivors showed temperature sensitivity of either growth or differentiation. Neither fusion into myotubes nor accumulation of any of the muscle specific proteins occurred at the non-permissive temperature. We had established that biochemical and morphological differentiations go hand in hand in these mammalian cells just as they do in Dictyostelium. As I was wrapping up the experiments I came to realize that all I had done was treat L6 cells just the way I treated Dictyostelium. However, even with the wonderful help of Denise Luzzati, I had been able to do far fewer myoblast experiments. Working with cultured mammalian cell lines was just intrinsically slower and far more expensive than working with Dictyostelium cells. I decided that myoblast differentiation was beautiful and an excellent experimental system but that Dictyostelium was better for me. I returned to La Jolla with renewed 
commitment to learn as much as possible about Dictyostelium development."

Based on the direction Bill took his investigations of Dictyostelium development, one can imagine that the use of enzyme accumulations as indirect markers of developmental events did not satisfy his curiosity about molecular mechanisms. The 1970's were a time where work in Bacillus subtilis spore differentiation was beginning to reveal molecular details of gene regulation at the level of modifications of its RNA polymerase (Losick and Pero 1976). Much of this work was coming out of the laboratory of Richard Losick, with whom Bill discussed developmental regulation at various venues.

Bill began dissecting developmental regulation at the molecular level by isolating and analyzing the spore coat protein genes and by examining proteins of the major cell types using two-dimensional gel electrophoresis. "David Cotter, a graduate student in Ken Raper's lab, had found out how to get spores to germinate synchronously. Using his technique, we could isolate the empty spore coats and then dissolve them in boiling SDS solutions. Electrophoretic separation in 1-D gels was sufficient to see that the major protein species had molecular weights of 96,000,70,000, and 60,000 Daltons. We named the proteins SP96, SP70 and SP60. Antibodies were raised to each spore coat protein and used for subcellular localization as well as cloning. Strains were isolated with mutations in one or more of the major spore coat proteins that helped to understand their roles in building the ellipsoid spore coats (Fosnaugh et al., 1994)." Bill's lab went on to show that the spore coat proteins were coordinately synthesized in prespore cells and packaged into prespore vesicles that fuse with the plasma membrane during culmination (Devine et al., 1982,1983).

\section{Cellular differentiation}

It was in the late 1970's that Bill turned his attention to cell differentiation and the control of cell type proportioning. Following the work of Harvey Lodish at MIT, Bill wanted to construct a more complete understanding of the proteins that were differentially expressed in prestalk and prespore cells. "A postdoc couple from Ireland, Kevin Devine and Barbara Dowds, picked up the saga and added higher resolution protein characterization and heroic cDNA cloning. Kevin used the 2-D technology that Jim Morrissey had established in the lab in which proteins are sequentially separated by isoelectric focusing and sized by gel electrophoresis. Kevin carried out several other interesting studies in the lab, including high resolution determination of expression of cell type specific proteins using 2-D gels and molecular characterization of anterior-like cells (Devine and Loomis 1985). "If you caught Bill in a nostalgic mood, he would pull out pictures of these old 2D gels. He drew unusual pleasure from re-discovering his favorite proteins on these pictures.

"Capitalizing on the specificity of the antibody to SP96 Barbara Dowds managed to clone a cDNA for this spore coat protein. This was the first successful cloning of a specific cDNA in the lab (Dowds and Loomis 1984). It was a heroic effort fraught with possibilities for failure. Thanks to Barbara, it worked. [Kathy Fosnaugh] wanted to understand how cell type specific genes were transcriptionally regulated in a eukaryote. She picked up the spore coat protein story where Kevin Devine and Barbara Dowds had left it and generated all sorts of new clones. The SP96 cDNA clone was used to establish a restriction map around the gene that directed subsequent isolation of genomic fragments encoding the full-length protein. Luckily, cloning the genes encoding the other spore coat proteins was more orthodox and straightforward. cDNA for SP60 was isolated by hybridization to oligonucleotides encoding the 6 amino acid sequence that is repeated four times near the N-terminus. CDNA for SP70 was recognized from clones that were enriched for expression in prespore cells. [Kathy] finished sequencing the $\cot A, \cot B$ and $\cot C$ genes and added about $1 \mathrm{~kb}$ to each of their upstream regions. She then subcloned different pieces of the regulatory regions and inserted them into expression vectors where they could drive $\beta$-galactosidase. Transformants were developed and the specific activity of $\beta$-galactosidase was measured every 4 hours throughout development. It became clear that there were independent cis-acting sites in the regulatory regions that worked additively without affecting the time of transcriptional initiation at 8 hours of development. She also found that barely functional regulatory fragments retained their cell type specificity; $\beta$-galactosidase activity was only found in prespore cells. Within each of these regions we could see a sequence closely related to CACCCAC. Kathy's results also clearly demonstrated that transcription as well as translation of the spore coat genes was coordinate under a variety of conditions, suggesting that these genes shared regulatory factors (Fosnaugh and Loomis 1993). One of her most interesting discoveries was that the cAMP dependent protein kinase PKA had to phosphorylate the transcription factor GBF to induce expression of the spore coat genes. These experiments were carried out in collaboration with Jeff Williams who had seen hints that this protein kinase was involved (Hopper et al., 1995)."

As we will describe below, Restriction Enzyme Mediated Integration (REMI) of plasmid DNA into the Dictyostelium genome made it easy to clone interesting genes (Kuspa and Loomis 1992). After the advent of REMI Bill became excited about the possibility of mutating all the developmental genes. We started to run Northern blots on RNA made at different points along the developmental time course of each REMI mutant and to analyze these blots with probes against the various developmental genes we discovered and with probes against $\cot B$ and ecmA. This work was laborious, and we used to fantasize about methods that would allow us to detect the mRNA levels of many genes at once. When gene expression measurements with microarrays became popular in the mid 1990s, Bill and Negin Iranfar developed a small microarray that they used to quantify mRNA abundance at different stages of development (Iranfar et al., 2001, 2003, 2006). Bill was very interested in precise measurements of gene expression and he selected his hybridization targets very carefully. We took a different approach at Baylor College of Medicine, and developed microarrays with large numbers of less-well characterized hybridization targets to serve as developmental phenotypes in the analysis of mutant strains (Van Driessche et al., 2002, 2005). These two different approaches were a source of friction between the UCSD and the BCM labs and we spent many hours arguing about them on the phone until our friendship was rescued by RNA-sequencing that allowed precise measurements of all the mRNAs in the transcriptome.

"Luckily, in 2008 RNA-seq came along and completely replaced microarrays for global transcriptional analyses. Gadi and I were thrilled to see the enormous dynamic range and reproducibility of RNA-seq data. We collaborated on repeating the time courses and cell type specificity measurements with the highest possible resolution. Every gene in dictyBase now has its quantitative $m R N A$ profile posted for a wide range of growth and developmental conditions."

Bill's interest in the control of developmental gene expression 
culminated in his collaboration with our laboratories on comparing the Dictyostelium developmental transcriptome with that of a distantly related dictyostelid, Dictyostelium purpureum (Parikh et al., 2010; Loomis and Shaulsky 2011). "Transcriptional regulation of orthologs was found to be highly conserved with respect to time of development, level of abundance and cell-type specificity. It seemed that evolutionary constraints on progress through the stages limited both drift and variation in transcriptional control. The genetic networks controlling these genes must be robust and flexible to have lasted this long. When it is necessary to choose a gene for further study from a set of similar genes, the decision can often be guided by choosing the $\mathrm{D}$. discoideum gene with the D. purpureum ortholog that shows the most similar transcriptional pattern. Anything conserved over 400 million years of evolution is likely to be fundamental to the survival of the species."

Bill was fascinated with cell-type specific gene expression. He enjoyed Kathy's work on the $\cot B$ promoter and he admired Jeff Williams' molecular analysis of the prestalk genes and the anatomy of the prestalk region. He was primed and ready when Mineko Maeda introduced the idea of generating an atlas of gene expression pattern in Dictyostelium development.

"Some of the most exciting results concerning transcriptional patterns came from an ambitious collaboration with Mineko Maeda. We were working with Mineko on the ERK2/PKA oscillatory circuit at that time and she often visited us in La Jolla. On one trip, she asked to see all the raw microarray data on cell type specificity with the idea of choosing several hundred of the best candidate genes for detailed in situ hybridization. The idea was to look for any changes in the spatial pattern of accumulation during development. When Ricardo Escalante was in the lab, he had optimized conditions for whole-mount in situ staining with cDNAs. Mineko proposed using his technique for each of the cell type specific genes. When I visited her lab at Osaka University in 2002, she dumped whole boxes of photos on the table in front of me. Many of the pictures were beautiful and showed the spatial pattern with high resolution. But there were too many genes and too much data to recognize general patterns. I remember getting up and going outside for air several times as we struggled with the results. After a few hours, certain recurring patterns became clear to me and I started clustering the genes on the basis of their cell type specificity at different stages. First, we separated the prespore and prestalk genes. There were only a few genes that started out in one cell type and then switched to the other. Most prespore genes gave simple patterns localized to the posterior cells. However, prestalk genes showed a wide range of different temporal and spatial patterns. Mineko and I spent the next day distributing the prestalk genes into 13 groups and choosing the pictures to illustrate the patterns we were seeing (Maeda et al., 2003). It was beginning to make sense, but it was also clear that Dictyostelium was not as simple a developmental system as it appeared."

Bill and Gadi met at a conference in West Berlin in 1989 and discovered a shared interest in the possibility that development and cell differentiation were competitive processes. Bill invited Gadi to join his lab as a postdoctoral fellow and their first joint project was aimed at addressing this question. "When Gadi arrived in La Jolla, I encouraged him to get used to the organism and the ways we treated it. He was particularly taken by one set of experiments: the old Raper microsurgical manipulations of slug tips and proportions of cell types that had suggested that the tip might act as an organizer region and that lateral inhibition of prespore differentiation in uncommitted cells might establish the proportions. We tried to come up with a genetic selection that would allow us to isolate REMI mutants in which the cell type proportions were abnormal or in which tip dominance was compromised. Gadi suggested that expressing ricin A from cell type specific regulatory regions might kill the cell type from within. Since ricin A cannot enter cells without its heterodimer partner [lectin] ricin B, there was no danger that release of the ricin from dying cells would kill adjacent cells or endanger us. Unfortunately, we never found conditions that gave sufficient selection such that we could get mutant strains. However, the strains expressing either the prestalk or the prespore specific vectors had very interesting phenotypes. Prespore specific expression of ricin A killed not only all the prespore cells but also the prestalk cells because they converted to prespores as the original population died. On the other hand, prestalk specific expression of ricin A resulted in the death of prestalk cells but did not affect the prespore cells. The results suggest that prespore cells compete with prestalk cells by producing an inhibitor of prespore differentiation to which they are insensitive."

With the development of increasingly sophisticated genetic technology (homologous recombination, insertional mutagenesis, and GFP-based transcriptional probes and protein fusions) Bill had access to a whole host of gene mutants obtained by insertional mutagenesis that turned out to be nodes in developmental regulatory pathways. He distributed the genes between trainees in his lab and invited collaborators from other labs to participate, hoping to gain deep insight into molecular mechanisms of developmental transitions. Bill often told us that one lab cannot study everything and that collaborations were fruitful and satisfying. The first detailed characterization of a REMI mutation was focused on lagC (aka tgrC1) (Dynes et al., 1994), which turned out to be a key regulator of the transition from unicellular development to multicellular tissue formation (Hirose et al., 2015). This work was done in collaboration with Joe Dynes in Rick Firtel's lab. Another fruitful collaboration with Robert Insall in the lab of Peter Devreotes described the $\mathrm{PH}$-domain protein CRAC and its role in chemotaxis (Insall et al., 1994). Adam and Jeff Segall characterized the aggregationless mutant erkB- (Segall et al., 1995) and Gadi and Adam characterized the synergizable tight aggregate mutant tagB-(Shaulsky et al., 1995). Others in the lab characterized the culmination gene dhkA (Wang et al., 1996), the cell-type sorting gene tipA (Stege et al., 1997), the slug migration gene migA (Escalante et al., 1997), the spore differentiation gene splA (Nuckolls et al., 1996) and the rapid development of the yel $A^{-}$mutant (Osherov et al., 1997). Bill then turned his attention (and ours) to the construction of developmental pathways.

An example of identifying a key node in the developmental network came from the development of suppressor screens using unbiased insertional mutagenesis (Shaulsky et al., 1996). "Gadi and Adam had shown that strains lacking either of the transporter proteases, TagB or TagC, were blocked at the mound stage and made almost no spores (Shaulsky et al., 1995). Therefore, rare survivors that sporulated could be selected and the suppressor mutation characterized. No matter what the suppressorgene turned out to be, it would help define the TagB and TagC pathways that were complete mysteries at that time. A single strong suppressor was isolated from a saturation mutagenesis and shown to result from inactivation of a previously unknown cytoplasmic cAMP 
phosphodiesterase, RegA. The extracellular phosphodiesterase, $P d s A$, had been known for years to play an essential role in CAMP signaling between cells, but no one had worried about controlling cAMP within cells. Further inspection of RegA also established it as a member of a two-component system in that it carries a response regulator region near its $N$-terminus. These regions accept phosphate that is relayed from a histidine kinase via a small H2 intermediate. It seemed likely that the phosphodiesterase activity was regulated by phosphorylation of the response regulator region. Since $\operatorname{tag} B^{-}$and tag $C^{-}$null mutants sporulated almost as well as wild type cells if they also carried the regA- mutation, we proposed that internal $C A M P$ bypassed the need for the transporter proteases possibly by activating PKA (Wang et al., 1996)."

Bill had the good fortune that the receptor histidine kinase for RegA, DhkA, was being studied in the lab at the same time that RegA was being characterized. "All we knew was that this gene, dhkA, was essential for sporulation and normal stalk formation and probably encoded a membrane embedded receptor. The amino acid sequence of DhkA suggested that it was able to autophosphorylate, adding a phosphate to a histidine moiety, and then transferring this phosphate to an aspartate further down its sequence. As we hoped, [Nancy Wang and Gadi showed that] DhkA was a true histidine kinase. We had no idea what its partner in a two-component pathway might be, but we had a candidate with a response regulator region, RegA. We started thinking that DhkA might be keeping internal cAMP and PKA low by stimulating RegA. In support of this idea, Nancy and Gadi were able to rescue sporulation in dhkA null cells by addition of cell-permeable cAMP. Somewhat later, we were able to show that sporulation could be restored to $d h k A^{-}$null cells by expressing constitutively active $P K A$. If we could find the intercellular signal that was recognized by DhkA, we could flesh out the pathway. For several years I had been talking to Michel Veron and his graduate student, Christophe Anjard, about small molecule signals generated by prestalk cells that induced sporulation in cells that were partially constitutive for PKA. We decided to test the putative pathway with these factors. Although loss of DhkA had no effect on the ability of the phosphopeptide SDF-1 to induce sporulation, it completely blocked the ability of the peptide SDF-2 to induce sporulation. Moreover, production of SDF-2 was completely dependent on the presence of TagC (Wang et al., 1996)."

"Nancy Wang, Christophe and Gadi carried out high resolution site-directed analyses of DhkA and showed that SDF-2 bound to an extracellular domain flanked by transmembrane regions and established exactly which histidine and aspartate were phosphorylated (Wang et al., 1999). When SDF-2 bound to DhkA, the protein kinase became a protein phosphatase, removing phosphate from RegA and leaving it much less active (Anjard and Loomis 2005). Christophe tried hard to purify sufficient SDF-2 for chemical determination but never succeeded. Finally, after 5 years, a genetic hint showed that SDF-2 was a peptide cut out of the well-conserved metabolic protein AcbA. Christophe spent the next 5 years working out the surprisingly complex set of interacting pathways involving steroids, GABA and glutamate that fine-tuned the temporal control of sporulation (Anjard et al., 1998; Anjard and Loomis 2005, 2006, 2008; Anjard et al., 2009, 2011)."

"Using his highly sensitive SDF-2 bioassay, Christophe was able to show that GRASP mediates unconventional secretion by using components of the autophagy pathway to position AcbA within vesicles that subsequently fuse with the plasma membrane to release their cargo. Together with Vivek Malhotra and Suresh Subramani he was able to show that this pathway is also used in the yeasts Saccharomyces cerevisiae andPichia pastoris. In both Dictyostelium and Pichia AcbA is secreted and processed into peptides that trigger rapid sporulation. The pathway also functions in mammals where the active peptide is called DBI, for Diazepam Binding Inhibitor. It is generated in the brain by proteolytic cleavage of $A c b A$ and binds to GABAA receptors on neurons at the site where benzodiazepines, such as Valium, bind. This is one of the most well studied signaling pathways in biology because Valium is one of the most frequently prescribed medications in the world. When evolution discovers a signaling pathway that works, it holds onto it almost forever. Guided by our observations in Dictyostelium, we were able to show that steroid hormones, such as cortisol, induce secretion of AcbA from astrocytes. The AcbA/SDF-2 story shows how studies in a model system can bring unexpected light to bear on an important biomedical process."

\section{Contributions to genetic methods}

Having had direct experience with the advantages that welldeveloped genetic systems afforded workers in Neurospora and E. coli, Bill was driven throughout his career to develop genetic techniques for Dictyostelium to aid developmental studies. "Developmental mutations are innately conditional in Dictyostelium since fruiting body formation is not an essential part of the life cycle. I was convinced that Dictyostelium could become a good genetic system when we learned how to efficiently generate mutations and cross strains." John Ashworth and Bill teamed up again when John went to UCSD on a Harkness Fellowship in 1967 and they worked out methods to carry out parasexual crosses. "[W]e set out to isolate heterozygous diploids from genetically marked mutant strains. We noticed that some of the survivors of NTG mutagenesis were barely able to grow. John had the insight to realize that each of the small plaque strains probably resulted from a mutation in a different gene and that most of these mutations would be recessive. Therefore, a diploid formed between two independent small plaque strains would grow at the wild type rate and form a large plaque that could be easily recognized on a plate with mostly small plaques. We systematically generated and characterized a set of minute mutants and crossed them with each other. Almost all pairs reproducibly gave rise to large plaques of diploids. Upon further subculturing these heterozygous strains gave rise to haploid progeny expressing the minute phenotype."Bill next developed strains that were temperature sensitive for growth $(t s g)$ at $27^{\circ} \mathrm{C}$ that could be used to select for diploids at the restrictive temperature. These worked much better than the minute strains because neither the diploid progeny, nor the haploid segregants from those diploids, had any growth advantage over the parent $t s g$ haploid strains at the permissive temperature (Loomis 1969).

Bill also developed, what were at the time, high throughput methods to screen clonal isolates of NTG mutagenized populations of amoebae. To accomplish this Bill first had to develop a strain that would grow axenically. Bill and John were unable to obtain such a strain from Sussman (AX1) so they isolated their own versions in 1968; John made AX2 in his lab in Leicester, while Bill isolated $A X 3$ at UCSD. Bill was now in a position to mutagenize AX3 and screen clones for any biochemical activity without interference 
of possible enzyme activity from the food bacteria. "I wanted to [use] the [lysosomal enzyme] "yellow" substrates to directly stain clones derived from mutagenized cells to isolate strains lacking the activity. The problem was that Dictyostelium cells do not stick to glass or plastic very well and are very motile. As a result they move around the surface of a petri dish and do not remain as pure clones. I found a solution to this problem by culturing them in the wells of microtiter plates. These plates were commercially available and used by immunologists for serial dilution. I put them to a completely different use. We learned how to efficiently fill each well with medium and inoculate them with a single viable cell as well as replica-plate the clones once they had grown up. We could then lyse the cells, add the substrates and score the activity in each well. Clones of interest could then be recovered from the replica plates. These techniques were soon picked up by other labs that recognized the utility of carrying out hundreds of independent biochemical reactions in a convenient format (Brenner et al., 1975)."

In the summer of 1972, Bill "had hundreds of 96-well plates incubating mutagenized Dictyostelium cells" and "had found several good candidates for mutations affecting $\alpha$-mannosidase. They were all shown to fall in the structural gene encoding the developmentally regulated enzyme (Free and Loomis 1974)." This technology allowed Bill and his colleagues to isolate mutations in the structural genes of a number of developmentally regulated enzymes as well as temperature sensitive mutants that were blocked at specific stages of development (Brenner et al., 1975). By the time we arrived in the Loomis lab in the early 1980's and early 1990's, the 96-channel pipets and 96-prong replicators were still in use, having been made in the machine shop around the corner from the lab in Bonner Hall at UCSD.

Parasexual genetics has given way to "physical genetics" now, where one constructs the strain of interest using sophisticated tools of site-directed mutagenesis, muti-gene knockouts, insertional mutants, suppressor screens, and CRISPR/Cas9. These modern tools would not be possible without another development that Bill promoted. "Steve [Cohen] and Dave [Knecht] built a plasmid with the regulatory region of actin15 driving the neomycin phosphotransferase I gene that confers G418 resistance. When they used their plasmid for transformation, it worked like a charm (Cohen et al., 1986). They went on to show that transcriptional regulation from actin 15 only requires the proximal 270 base pair region (Cohen et al., 1986). Wolfgang [Nellen] decided to make his own transformation plasmid using the actin6 regulatory region to drive neomycin phosphotransferase II (Nellen et al., 1984). This plasmid worked very well. As we compared results over lunch, it became apparent that both the actin6 and the actin15 essential regulatory regions carry a sequence closely related to AATGGGATTTT, which is also found upstream of many other actin genes. Steve, Dave and Wolfgang targeted this sequence in a series of deletions and point mutants that showed that it was essential for expression of adjacent genes (Nellen et al., 1986; Cohen et al., 1986). This was the way to get to the gene regulatory network."

"However, we needed molecular genetic techniques to be able to get to the underlying molecular mechanisms of development in Dictyostelium. [The Firtel lab] transformed cells with a construct in which a gene encoding the discoidin lectin was inverted relative to the promoter and showed that [these antisense strains] had the same phenotype as discoidin-1 minus mutants (Crowley et al., 1985). We hoped to develop a way to knock down most develop- mental genes and determine the consequences. Knocking down the gene encoding myosin heavy chain, $m h c A$, sounded like a good place to start. The role of myosin was of great interest unto itself and the Dictyostelium genome was known to have only a single gene encoding the heavy chain. [Jim Spudich] was convinced that knocking out myosin would kill the cells. I told him about driving mhcAantisense with the actin15 promoter that was much less active in growing cells at low cell densities. Dave Knecht picked up the clone and rapidly generated an antisense transformation vector. He put the transformed cells in petri dishes containing medium with G418. After several weeks, colonies could be seen on the bottom of most plates [and] we soon learned that the mhcA antisense cells cannot grow in suspension; cell division is impaired and the cells all become highly multinucleated and die. On the surface of petri dishes they can attach and pull themselves apart to give rise to daughter cells. It seems that Dictyostelium cells absolutely need myosin heavy chain to divide in suspension but not when they are attached to a substratum. It also seems that antisense successfully knocked down myosin heavy chain. "Since the Spudich lab worked mainly on myosin function Jim's student at the time, Arturo De Lozanne, traveled to UCSD to join the project. "Dave and Arturo made variations in the original antisense plasmids, changed the length of the region that would be transcribed in the reverse direction as well as prepared plasmids that would be transcribed in the sense orientation to use as controls. They recovered a whole set of new transformants and characterized them for myosin accumulation using antibodies specific to myosin that had been prepared in the Spudich lab. After a few months, Arturo felt he had learned enough to solo, and returned to Stanford. A few weeks later, I got an excited phone call from Arturo telling me that he thought one of the transformants had undergone homologous recombination in the myosin [structural] gene. His restriction digests were messy but it looked as if the structural gene was disrupted. The strain was able to grow on petri dishes but not in suspension and so was likely to be an mhcA mutant. Was it really a case of homologous recombination with the transformation vector? A few days later Arturo called back with clean proof of homologous recombination. This was such an important advance in the molecular genetics of Dictyostelium that we agreed to hold offon publishing our antisense results until we could publish together back to back with Arturo and Jim. It was not until May 1987 that our papers came out in Science but the wait was worth it. For one thing, it made it very clear that antisense could be accurately aimed at a single gene with no offtarget effects since the phenotypes of the antisense cells and the homologous knockout were identical."

"Jim Spudich and I were well aware that we had the good fortune to be the first to have non-muscle cells that were unable to make myosin. We knew that the cells could not divide in suspension, but what else besides cytokinesis might be affected? We recruited Peter van Haastert and David Soll to help characterize both the antisense and the knockout strains. We found that chemotaxis, signal relay, actin polymerization, and expression of cell type specific marker genes were all essentially normal. Although the cells were still motile, they moved at about half the speed of wild type cells. The fact that these cells moved at all meant that some other motor system must be at work. Subsequent work, mostly in the laboratory of Meg Titus, characterized a dozen genes encoding unconventional myosins and showed that some of these played essential roles in amoeboid motion. Mutational based studies in 
Dictyostelium took the lead in this field."

"I was increasingly convinced that one of the best ways to unravel complex processes was to use mutational genetics to collect the pertinent genes in an undirected, unbiased manner."

After a couple of years of trying to get insertional mutagenesis working so that we could identify genes by their phenotype and clone them efficiently, Bill stumbled on a breakthrough and pointed it out to one of us. "Adam [Kuspa] tried randomly inserting a plasmid that carried genes for pyrimidine biosynthesis by selecting transformants from a pyr5-6 mutant strain for growth in the absence of added [uracil]. He could get transformants that carried the plasmid but very few showed any phenotypic abnormality. However, he picked a few of the apparent mutants and characterized their insert sites. The insertion site in one of them appeared to be a perfect EcoR1 site. That was curious because the plasmid had been opened with EcoR1 to generate linear DNA. I suggested that he might try leaving the restriction enzyme there next time and see if it increased the frequency of integration in EcoR1 sites. He thought this was not a particularly good idea because there was no evidence that enzymes entered cells during electroporation and, even if they did, EcoR1 might easily kill the host cell by cutting up its genome into small 400 bp fragments."

"A day or two later I was browsing through PNAS and ran into a paper by Schiestl and Petes describing "illegitimate recombination" in yeast when they introduced the restriction enzyme BamH1 along with a selectable plasmid (Schiestl and Petes 1991). More than half the insertions were at BamH1 sites. I gleefully brought the paper to Adam. Within the next few days he repeated the experiments with Dictyostelium and had immediate success: the frequency of recovery of transformants was increased more than 20-fold, about two thirds of the insertions were in sites recognized by the specific restriction enzyme that had been used, and 1 in [100] of the transformants showed noticeably variant morphology. The plasmid was isolated carrying flanking regions from the mutant strain and used to recapitulate the mutant phenotype by homologous recombination. We named this technique for tagging genes REMI, which was an acronym for Restriction Enzyme Mediated Integration (Kuspa and Loomis 1992). Then we opened a bottle of Remy Martin brandy in celebration. For the last 25 years REMI has significantly facilitated the study of Dictyostelium genes and has also been useful for the isolation of mutated genes in filamentous fungi and certain plant pathogenic fungi."

"By 1995 molecular genetics in Dictyostelium had matured to the point where just about any genotype could be rapidly generated. We could knock out or modify specific genes at will. We could determine the subcellular localization of any protein of interest by fusing it to Green Fluorescent Protein. We could modify the stage of expression of a gene by driving it with an exogenous regulatory region. We could select fornovel mutants from a REMI mutagenized population and have the genes cloned within a month. The idea was not just to accumulate important developmental genes, but to weave them into pathways and circuits that regulate morphogenesis. At last Dictyostelium was a fully accredited genetic model system. All that we needed was the sequence of the genome."

\section{Evolution and genomics}

Bill had a keen interest in evolution throughout his career, no doubt inspired by discussions with UCSD colleagues Harold Urey and Stanley Miller on the topic of prebiotic chemistry. One of Bill's first publications in the field was a book that described his ideas about how life evolved on the planet; "Four billion years: an essay on the evolution of genes and organisms" (Loomis 1988). Bill also conceived of ingenious ways to test some of his ideas about genome evolution that were initially separate from his experimental work with Dictyostelium. When Bill did turn his sights on the phylogeny of Dictyostelium his analyses resulted in the radical proposal that the dictyostelids were a sister clade to the Metazoa and Fungi. About ten years later whole genome sequencing efforts would confirm Bill's proposal and would also demonstrate that the Amoebozoa are a monophelytic clade including the dictyostelids (Baldauf et al., 2000, Bapteste et al., 2002).

"I had a long term interest in the structure and evolution of genomes. I had come to appreciate that new genes mostly resulted from divergence of duplicated genes. This required a lot of duplication and deletion to keep the genome stabilized. However, deletion is inherently more dangerous than duplication because having more than enough of a gene product is seldom detrimental while deleting a gene is potentially lethal. If the rate of duplication is about the same as the rate of deletion and the positions of the ends are random, then there has to be a high proportion of [dispensable] DNA to provide neutral end points for many of the deletions. I realized that this thinking could explain what people were calling the ' $C$-Value Paradox' - the observation that the total amount of DNA in different species did not correlate with the complexity of the species and that many species had much more DNA than necessary. I thought I might be able to convince people to consider the role of vestigial DNA by treating the problem mathematically. I got in touch with my UCSD colleague Mike Gilpin who is a mathematician interested in evolution. He considered the problem and soon told me that he could not solve it analytically but could write a computer program that would iteratively simulate a genome over 30,000 generations. The final artifactual genome was about the same size as a mammalian chromosome. Many genes were present in multigene families, much like the actin and Ras genes in Dictyostelium, and about 50 to $90 \%$ of the sequence was dispensable. The proportion of dispensable DNA depended on the relative rates of duplication and deletion. The analysis predicted that the rate of deletion was higher in the smaller Dictyostelium genome." The simulations of genome evolution by Loomis and Gilpin provided evidence that 'vestigial sequences' were a natural consequence of duplication and deletion events (Loomis and Gilpin 1986). Their observations were later confirmed when the genome sequence of Dictyostelium discoideum was determined, where many of the genes exist in contiguous clusters greater than three genes each (Eichinger et al., 2005).

Bill was also keenly interested in the phylogeny of Eukaryotes, both from a purely intellectual perspective and from the more practical desire to understand how relevant findings in Dictyostelium would be to human biology. "In 1983 Sogin and Woese published that Dictyostelium was one of the earliest branching organisms, apparently leaving the line leading to plants and animals long before other eukaryotes (McCarroll et al., 1983). After thinking about the technique of sequence comparison for a while, I realized that Sogin and Woese could have been misled about the relative time of divergence of Dictyostelium because there was a big difference in the GC content of the ribosomal RNAs. The Dictyostelium genome had been known for some time to have one of the lowest 
GC contents ever encountered. This bias had spread into the rRNA sequences where compensatory mutations could maintain the essential secondary structure of stem-loop modules. Comparing a low GC RNA sequence to a high GC sequence would show a huge divide that would be interpreted as early divergence. However, comparison of proteins in Dictyostelium and their homologs elsewhere should not be affected by difference in GC content even though codon usage might differ. I was curious what the phylogeny would look like if a half dozen or so proteins with homologs in the major phyla were compared."

"One of my colleagues at UCSD, Doug Smith, had become good at protein sequence comparisons and offered to help in establishing the proper position of Dictyostelium among eukaryotes. He searched the available databases for homologs of one or more of the small number of Dictyostelium genes that were available in 1988. He needed a cluster of homologs that included at least one animal, one plant, one yeast, and a Dictyostelium gene. Trees built by two independent techniques, distance matrix and parsimony, were found to agree to all extents and purposes for each of these 8 clusters. Plants and yeast were found to diverge first, followed by Dictyostelium, Drosophila, nematodes and ending with mammals. We concluded that Dictyostelium diverged shortly after the split of plants and animals, and was certainly not an 'early diverging' species (Loomis and Smith 1990, 1995). This was important if we were to convince people that biological properties in Dictyostelium were sometimes relevant to biomedical problems. The phylogenetic arguments have improved over the years as the databases have expanded, culminating in whole genome comparisons in 2005. It is now well established that Dictyostelium shared a common ancestor with animals more recently than plants and that it carries orthologs of many animalgenes that are missing in yeast (Baldaufet al., 2000, Bapteste et al., 2002, Eichinger et al., 2005)."We now know that within many monophyletic clades such as the Amoebozoa there are species with genomes that span the entire protein-coding limit of GC content from low GC to high GC. This strongly supports Bill's concept that subtle differences in the properties of the DNA metabolizing enzymes could drive individual species' genomes to drift to extremes of GC content while selection at the protein level would maintain the essential functions of highly integrated biochemical and cellular pathways.

As complete genome sequences became available Bill worked with Rolf Olsen to extend eukaryotic phylogenetics with the comparison of complete proteomes. "Rolf had been a physics major in college but had then quit academics and survived by driving a taxi. After a while, he decided he really needed a $\mathrm{PhD}$. and so enrolled at UCSD. He was an excellent mathematician and thought that statistical mechanics was great, but the good problems were in biology. He became interested in how amino acid sequences evolved in proteins of diverse organisms. This led logically to phylogenetic comparisons of homologous proteins and finally to a whole new way to measure the degree of similarity among proteins derived from a common ancestral protein. I encouraged Rolf to pursue his ideas and found myself getting deeper into his new approaches. Rolf continued to develop his multi-matrix model of protein divergence and rigorously determined clusters of orthologs from organisms that last shared a common ancestor over a billion years ago. A cluster of 7 archaebacteria was used as the outgroup to root a tree of all eukaryotes. Twenty-three eukaryotes representing plants, animals, fungi, amoebozoa and early diverg- ing species with well-sequenced genomes were analyzed using several thousand clusters of orthologs. The final tree had highly significant nodes and reproducible branch lengths that have not been challenged or improved ever since. His trees grace both the Nature paper presenting the Dictyostelium genome and the PLoS Computational paper comparing the Dictyostelium genome to that of another Amoebozoa, Entamoeba histolytica (Eichinger et al., 2005, Song et al., 2005)." It would be nice to add species to the tree but in the last round, in which Entamoeba data was added to the 30 original species, the program ran for five days on the San Diego Supercomputer.

Bill also contributed in many ways to the physical mapping and sequencing of the Dictyostelium genome. Along with several other laboratories, Bill parasexually mapped a number of genes along the six linkage groups that were later shown to represent the six chromosomes (e.g., Morrissey and Loomis 1981). He also mapped the chromosomes with megabase-scale restriction fragment length polymorphisms (RFLPs) (Kuspa and Loomis 1994), tiled the genome with yeast artificial chromosome (YACs)(Kuspa and Loomis 1996) and, he spearheaded the US effort to sequence and analyze the genome (Eichinger et al., 2005). We started in 1989 by tiling the genome with ordered YAC clones in order to create a detailed physical map and because we thought they would be useful for ultimate sequencing. About 14 years later, light sequencing of plasmid sub-libraries from these YACs proved to be essential to the assembly of chromosome-sized contigs that could be mapped on to the chromosome maps, when it became clear that contigs based on paired-end sequences of clones from plasmid libraries had many gaps. "Our mapping set of 1,000 YACs provided more than fivefold redundancy for the 34-Mb Dictyostelium genome. We approached this project in an industrial manner, buying programmable large flatbed contour-clamped homogeneous electric field (CHEF) electrophoresis machines where we could electrophoretically separate large DNA fragments from 360 independent clones at a time. Each of the blots was sequentially probed [and] YAC contigs started to form when we found probes that connected a half dozen different YACs. Some of the first genes that we positioned on the YACs were ones that had been previously assigned to one or another of the six chromosomes on the basis of segregation patterns from heterozygous diploids. This established the chromosome identity of the YAC contigs (Kuspa et al., 1992). I don't know why we were such fanatics but the challenge was clear and we just kept going. We decided that it must be that we enjoyed mapping for its own sake. There is something rather rewarding about a straightforward problem where the answer is known to be a simple one-dimensional string of loci. We just had to find the right sequence of loci. At other times, we joked that whatever we did, when we published it, we could only be wrong (Kuspa and Loomis 1996). But it would help get funding for the ultimate mapping - sequencing the genome."While Adam was too involved in the mapping progress to enjoy Bill's reactions to the process, Gadi noted that Bill's attitude towards the genome mapping Southern blots was quite similar to his attitude towards the older 2D gels - he loved comparing images and finding overlapping signals as evidence of congruence.

In the mid 1990's Bill finished a physical map of the Dictyostelium genome by himself. "For several months I wrestled with the long-range restriction maps, REMI-RFLP maps, YAC contigs and chromosomal assignments. People have asked me what program 
I used to generate the final maps. I have had to say that it was all done in my head because the major differences in the types of information that had to be integrated were completely incompatible with any known program. Finally, with the telomeres and centromeres delineated, I reached consensus maps for each of the six chromosomes with no glaring internal inconsistencies (Loomis et al., 1995). We could see how to check the maps and remove the errors, but it would entail almost as much work as generating the maps in the first place. We decided that the sensible thing would be to sequence the whole genome and find discrepancies that way. Moreover, it was becoming very clear that the genome sequence was so useful that Dictyostelium would not remain an organism of choice for cell and developmental biology if we did not sequence it within the next 10 years. Rather than doing any further mapping, Adam and I set out on a campaign to get the funding and expertise to sequence the 34-Mb genome."

Bill was instrumental in the Dictyostelium sequencing project and he co-directed the US effort with our labs and Richard Gibbs, the founding director of the Human Genome Sequencing Center at Baylor College of Medicine. He was also an enthusiastic annotator of gene families and analyzed the ABC superfamily well before the genome sequence was completed (Anjard and Loomis 2002) and organized and co-edited a book on the $D$. discoideum genome (Loomis and Kuspa 2005).

\section{Control of cell motility}

Bill investigated various aspects of cell motility in the second half of his career. In this work, Bill continued to conceptualize biological regulation as a series of decision points within interconnected pathways, only instead of them occurring over hours of developmental time and between cells, these occurred over seconds within the cell. Bill advanced our understanding of the role of cell-cell adhesion, cell-substrate adhesion, and myosin II in motile functions, he advanced a potential molecular circuit explaining cAMP oscillations, and helped to refine models of gradient sensing and amoeboid chemotaxis. In this work, he integrated his deep understanding of enzyme kinetics, his love for complex models and his ability to collaborate effectively with quantitative science experts.

"Rick Firtel and Peter Devreotes were making rapid progress in understanding how gradients of exogenous CAMP direct movement of the cells into aggregates (Parent and Devreotes 1999, Chung et al., 2001). Work in their laboratories had defined a set of G protein coupled receptors (GPCRs) that bound cAMP with different affinities and transduced the signal through [PI3-kinase], PTEN and TORC2 to the regulation of F-actin polymerization. They were able to account for the subcellular localization of the signal in a satisfactory manner but had not accounted for the observed 6-minute periodicity in the relay of the CAMP signal. I started thinking about possible circuits that could generate an oscillatory signal and focused on the feedback of PKA activity on the inhibition of RegA by Erk2. It had recently been shown that activation of the CAMP receptor CAR1 by ligand binding stimulated Erk2 activity. Ligand binding to CAR1 was also known to activate the adenylyl cyclase ACA to make CAMP more rapidly. I reasoned that inhibition of RegA would lead to the rapid accumulation of CAMP that would activate PKA activity. Feedback loops from PKA to RegA inhibition and ACA activation could then reduce the CAMP level and PKA activity would fall back to the unstimulated level. I was sure this circuit could account for the oscillations in CAMP. An exceptional undergraduate, Mike Laub offered to help if I would teach him how to do experiments in the lab. I wrote out seven differential equations describing the temporal changes in the activity of five proteins and the consequences to internal and external cAMP concentrations. After we had set the parameters, we found that the circuit generated pulses in external CAMP with a 7-minute periodicity. One of the reasons that the circuit worked so well is that the kinetic terms describing the inhibition of the regulated proteins, CAR1, $A C A$, Erk2, RegA and PKA, were all first order in the activity being considered. Activation terms were all zero order. Mike and I were convinced that we had uncovered the basic oscillatory machine (Laub and Loomis 1998)."

"Thinking about PKA, I started to wonder what role it might play in motility of the cells during chemotaxis. My friend and colleague David Soll was the expert in computer assisted analysis of cell motility and he offered to analyze strains with constitutive PKA activity, resulting either from the loss of the phosphodiesterase RegAor with null mutations in the gene encoding the regulatory subunit of PKA. I sent the appropriate strains to Deb Wessels in his lab and waited patiently to hear if motility was affected or not. They used a series of tests for response to temporal waves, spatial waves, and natural waves. Both the regA- null cells and the pkaR cells were able to determine the direction of spatial gradients and could distinguish rising and falling concentrations of cAMP. However, neither strain was able to suppress lateral pseudopods during the response to an increasing temporal gradient and, as a consequence, showed very poor chemotaxis in a natural wave (Wessels et al., 2000). When PKA activity stays constitutively high, filamentous myosin does not localize to the cortex as it normally does."

"I suggested that we look at mutants lacking the adenylyl cylase, ACA, where PKA activity would be very low. [David] agreed and to our surprise [Deb] found that these cells behaved in a manner that was almost identical to the reg $A^{-}$null cells and the pkaR- cells. They also failed to suppress lateral pseudopods in the front of a wave and so staggered around. Yet unlike the regA- null cells and the pkaR cells, the acaA-cells had low internal cAMP. It seems that good chemotaxis depends on the Laub-Loomis circuit generating oscillations in CAMP and PKA activity."

"In 2002 the annual Dicty meeting was held in Palermo, Sicily. I remember being excited when Mineko Maeda showed me a Western blot stained with antibodies to activated Erk2 that showed spontaneous oscillations in phase with oscillations in cAMP. Further discussions with Adam and Gadi uncovered that we had amassed a diverse set of experimental results in different labs that all had bearing on the Laub-Loomis oscillatory circuit. We decided to pool our results and write up a paper on the experimental support of the architecture (Maeda et al., 2004)."

"Since 1990 I had been discussing chemotaxis and development of Dictyostelium with Herbie Levine, a theoretical physicist in the Physics Department of UCSD interested in non-equilibrium dynamics. At one point Herbie tried doing experiments in my lab but soon found that he was not cut out for time consuming minutiae or attention to boring details. Meanwhile, he successfully modeled spatial patterns and brought further insight into the nature of spiral waves of aggregating cells (Levine et al., 1996, Rappel et al., 1999, Nicol et al., 1999). At some point we realized that if he were to make further significant advances we needed to know how the cells moved and sorted out." 
"I had been aware for some time that Dictyostelium cells are able to greatly amplify the information presented by a shallow gradient such that they move almost directly towards the source. We wanted to figure out the biochemical basis for this amplification. By 2008 work in the laboratories of Gerry Weeks, Rick Firtel, Peter van Haastert and Peter Devreotes had convincingly shown that one of the first responses to CAMP binding to CAR1 was the preferential activation of Ras at the front of cells. This small GTPase is membrane bound and only active in the GTP bound form. Activated Ras can stimulate [PI3-kinase], TORC2 and other kinases upstream of F-actin regulation. A specialized exchange factor called GEF can lead to the replacement of GDP by GTP in Ras. The intrinsic GTPase activity of Ras converts GTP to GDP by hydrolysis of the terminal phosphate. However, this resetting of Ras is very slow in the absence of a specialized activating protein called GAP. When mulling this around, it occurred to me that if ligand binding to CAR1 activated not only the GEF but also the GAP, their opposing activities could give almost all-or-none responses depending on which activity was stronger at a given instant. I did not know it at the time, but this is an example of an incoherent feedforward loop. If the activating and inhibiting activities are balanced such that they cross each other when conditions change then the response can be ultrasensitive. This mechanism can account for signal amplification. The last step in building this intellectual construct was to get it to give directionality. I realized that if diffusion of the GEF within the cell were limited as a result of it being membrane localized and the GAP was a freely diffusing cytoplasmic protein then Ras-GTP would be stably amplified in a gradient at the front of cells while Ras at the back would remain in the GDP inactive form. This was just a variant of the LEGI [Iocal excitation, global inhibition] model that Peter Devreotes and Carole Parent had been proposing for a number of years. I was sure that it would work but now we had to prove it."

"Monica Skoge, who had just finished her graduate work with Ned Wingreen and Ted Cox at Princeton, was quite familiar with Dictyostelium, microscopy, and writing computer code. She was well prepared to acquire high-resolution quantitative live-cell images of cell polarity, chemotaxis and motility. She used a transformed cell line of Dictyostelium that expressed a GFP-coupled protein that bound Ras-GTP but not Ras-GDP. Images were collected every 2 seconds for 30 minutes to accurately define the position of RasGTP. Patches of RasGTP were seen at the tip of all active pseudopods. Only when a pseudopod was being retracted did the patch of RasGTP disappear. Wouter Rappel, Herbie Levine and one of his students, Inbal Hecht, formulated a model for amoeboid cell motion in which activated RasGTP determined the location of membrane protrusion, taking into account cortical tension and the availability of protrusion resources. Some of the parameters of the equations were constrained by direct measurements. For instance, the half-life of a RasGTP patch was less than 2 seconds when the gradient was rapidly turned off. When the gradient was re-established, the RasGTP patch rapidly reappeared indicating that both the RasGAP and the RasGEF were very active. The equations were numerically solved and coupled to an animation program that generated a little cell that ran around chasing CAMP gradients much as cells do in the real world (Hecht et al., 2011)."

"One of the unsolved mysteries of aggregation was accounting for the continuous forward movement of cells as they encountered a series of travelling waves of CAMP. As a wave passes over a cell, the direction of the gradient changes from front to the back, yet the cell keeps moving in the same direction for at least two minutes in the back of the wave. It seems that each cell has a memory of the direction it determined when the concentration was increasing which overcomes signals from the back when the concentration is decreasing. Alex Groisman designed a microfluidic wave machine so that we could characterize cells in cAMP waves of well-defined periods and concentrations. Monica showed that persistent movement in the back of waves was a developmentally controlled capability. Cells that had developed for 3.5 hrs were chemotactic but stopped at the peak of waves and just dithered around. On the other hand, cells that had developed for 5 hrs continued to move forward in the back of waves and showed uninterrupted progress in waves with 6-minute periods. As predicted by the mathematical simulations, the RasGTP patches disappeared in the back of the wave. Therefore, to account for the persistence of motility, we had to add a bistable memory module to the equations (Skoge et al., 2014). Experiments with the wave machine as well as other microfluidic devices with rapid gradient reversals produced a wealth of kinetic measurements that could be used to challenge the mathematical modeling. I could estimate the outcomes of the models in my head and was confident that our present version could account for the results from all the diverse experiments, but I was very happy to hear from Wouter that equations using the same set of parameters worked equally well for the kinetics of adaptation to global stimulation as for the kinetics of RasGTP patch persistence under changing CAMP gradients or even in the cAMP waves generated in our microfluidic machine (Bhowmik et al., 2016). Since one model could account for all these different behaviors, it was likely that the model captured the essence of the cell. It was also rewarding to see that the model produced the ultrasensitivity that could account for amplification."

"It is impossible to consider the mechanical forces that result in cell movement without including the traction needed to transmit the work to the substratum. The prevalent opinion held that Dictyostelium cells, like mammalian mesenchymal cells, must generate traction by using surface receptors that bind to immobilized proteins. It was well established that mammalian cells use heterodimeric combinations of integrins to bind to extracellular matrices. But I knew from searching the genome that Dictyostelium did not carry genes encoding homologs of integrins or the extracellular matrix proteins that they recognized. Something else must provide adhesion to substrates. Alex Groisman agreed to modify a microfluidic device that he had designed for studies with yeast cells so that we could quantitatively measure the resistance of Dictyostelium cells to hydrodynamic shear stress. The device has 8 chambers in which the flow rate doubles from one chamber to the next. We imaged fluorescently labeled cells every minute and found that the rate of detachment was directly proportional to the shear stress. The surprising thing was that it didn't matter what surface they were on - naked glass, plastic, Teflon, silanized glass or protein coated glass. The cells seemed to have an innate ability to bind to just about anything. Having ruled out covalent or hydrogen bonding as well as ionic or hydrophobic interactions, what were we left with? A friend of Herbie's, Len Sanders, suggested that we consider van der Waals attractions. The biophysics of van der Waals attractions between surfaces has an intellectual history and theoretical underpinning. However, it is essentially impossible to predict with confidence whether one surface will be more attrac- 
tive than some other surface. On the other hand, it is possible to predict small molecules that can interfere with attraction between surfaces of known composition. We found that either monomeric sugars or amino acids were effective in reducing cell substratum adhesion indicating that surface glycoproteins generated the induced dipoles of the van der Waals attraction. The results indicated that Dictyostelium cells generate innate adhesion by van der Waals attraction although they do not rule out the possibility that receptor-ligand based adhesion might be added on top (Loomis et al., 2012). Since our results have considerable biomedical importance, we didn't want to be fooled by systematic errors in the assay and sought out an independent way to test cell-substratum adhesion. One day I was talking with Eberhard Bodenschatz at a meeting and he mentioned that a postdoc in his lab, Marco Tarantola, was trying to use an atomic force microscope to measure cell-substratum adhesion forces. Marco showed me his results at a Gordon Conference in the Swiss Alps and we quickly recognized how our assays complemented each other. The following summer he came to La Jolla for a few months and essentially repeated all the experiments [we] had done with hydrodynamic shear assay. Marco's technique depended on his coating the tip of an atomic force microscope with a strong organic glue that attached to cells when it touched them. He would then lift a cell and lower it onto a clean area of the substratum before measuring the force necessary to dislodge it. This assay measures the resistance of a cell being pulled up rather than the resistance of a cell to being blown away. With various normalizations and standardizations the two techniques gave essentially the same results (Tarantola et al., 2014)."

\section{Concluding remarks}

Bill passed away on June 30, 2016 in his office at UCSD, while writing his last scientific perspective about the rebirth of chemical mutagenesis in Dictyostelium in the genomic era (Loomis 2016a). It was a bittersweet ending to a life that has been devoted to science and to the friends who helped him enjoy it so much. Bill was scientifically rigorous, as might be expected from one who had trained at Harvard, MIT and Brandeis, but he was also imaginative and driven by an insatiable curiosity that was infectious to many of his colleagues and trainees (including the authors). Bill was a very selective mentor - he would deliberately discourage students and postdocs from joining his lab to make sure he only trained the most dedicated scientists. He treated his colleagues in the same way, collaborating only with those whom he found sufficiently inquisitive and rigorous. To those of us who were fortunate to benefit from his mentorship, he was a demanding but nurturing mentor who gave us the freedom to explore whatever we found interesting while making sure we made our best effort in doing so.

\section{Afterword}

The opinions that we have expressed here were derived largely from direct discussions with WFL. AK worked with WFL from 1979-1983 as an undergraduate student at the UCSD and from 1989-1993 as a postdoctoral fellow, while GS worked as a postdoctoral fellow with WFL from 1991-1997. The three of us had lunch together almost everyday while we were all at UCSD and Dictyostelium was the topic most of the time. Both AK and GS continued to collaborate with WFL after each of us moved to Baylor College of Medicine, publishing a total of 38 papers together. WFL's creative insights into Dictyostelium biology continue to inspire our work.

\section{Copyright note:}

Extensive extracts from Loomis' "My life with Dicty", originally posted on the DictyBase as an unpublished personal communication, have been reproduced with the permission of the DictyBase community listerve workgroup.

\section{References}

ANJARD C, LOOMIS W F (2002). Evolutionary analyses of ABC transporters of Dictyostelium discoideum. Eukaryot Cell 1: 643-652.

ANJARD C, LOOMIS W F (2005). Peptide signaling during terminal differentiation of Dictyostelium. Proc Natl Acad Sci USA 102: 7607-7611.

ANJARD C, LOOMIS W F (2006). GABA induces terminal differentiation of Dictyostelium through a GABAB receptor. Development 133: 2253-2261.

ANJARD C, LOOMIS W F (2008). Cytokinins induce sporulation in Dictyostelium. Development 135: 819-827.

ANJARD C, SU Y, LOOMIS W F (2009). Steroids initiate a signaling cascade that triggers rapid sporulation in Dictyostelium. Development 136: 803-812.

ANJARD C, SU Y, LOOMIS WF (2011). The polyketide MPBD initiates the SDF-1 signaling cascade that coordinates terminal differentiation in Dictyostelium. Eukaryot Cell 10: 956-963.

ANJARD C, ZENG C, LOOMIS W F, NELLEN W (1998). Signal transduction pathways leading to spore differentiation in Dictyostelium discoideum. Dev Biol193: 146-155.

BALDAUF S L, ROGER AJ, WENK-SIEFERT I, DOOLITTLE W F (2000). A kingdomlevel phylogeny of eukaryotes based on combined protein data. Science 290: 972-977.

BAPTESTE E, BRINKMANN H, LEE J A, MOORE D V, SENSEN C W, GORDON P, DURUFLE L, GAASTERLAND T, LOPEZ P, MULLER M, PHILIPPE H (2002). The analysis of 100 genes supports the grouping of three highly divergent amoebae: Dictyostelium, Entamoeba, and Mastigamoeba. Proc Natl Acad Sci USA 99: 1414-1419.

BHOWMIK A, RAPPEL W J, LEVINE H (2016). Excitable waves and directionsensing in Dictyostelium discoideum: steps towards a chemotaxis model. Phys. Biol. 13: 016002.

BRENNER M, TISDALE D, LOOMIS W F (1975). Techniques for rapid biochemical screening of large number of cell clones. Exp Cell Res 90: 249-252.

CHUNG C Y, FUNAMOTO S, FIRTEL RA (2001). Signaling pathways controlling cell polarity and chemotaxis. Trends Biol. Sci. 26: 557-566.

COHEN S M, KNECHT D, LODISH H F, LOOMIS W F (1986). DNA sequences required for expression of a Dictyostelium actin gene. EMBO J 5: 3361-3366.

CONANT J (2002). Tuxedo Park:AWall Street Tycoon and the Secret Palace of Science That Changed the Course of World War II. Simon and Schuster, New York, NY

CROWLEYTE, NELLEN W, GOMER RH, FIRTELRA(1985). Phenocopy of discoidin I-minus mutants by antisense transformation in Dictyostelium. Cell 43: 633-641.

DEVINE K M, BERGMANN J E, LOOMIS W F (1983). Spore coat proteins of Dictyostelium discoideum are packaged in prespore vesicles. Dev Biol 99: 437-446.

DEVINE K M, LOOMIS W F (1985). Molecular characterization of anterior-like cells in Dictyostelium discoideum. Dev Biol 107: 364-372.

DEVINE K M, MORRISSEY J H, LOOMIS W F (1982). Differential synthesis of spore coat proteins in prespore and prestalk cells of Dictyostelium. Proc Natl Acad Sci USA 79: 7361-7365.

DOWDSB.D.A, LOOMISW.F (1984). Cloning and expression of a cDNAthat comprises part of the gene coding for a spore coat protein of Dictyostelium discoideum. Mol Cell Biol 4: 2273-2278.

DYNES J L, CLARK A M, SHAULSKY G, KUSPA A, LOOMIS W F, FIRTEL R A (1994). LagC is required for cell-cell interactions that are essential for cell-type differentiation in Dictyostelium. Genes Devel 8: 948-958.

EICHINGER L, PACHEBAT J A, GLOCKNER G, RAJANDREAM M A, SUCGANG R, BERRIMAN M, SONG J, OLSEN R, SZAFRANSKI K, XU Q, TUNGGAL B, KUMMERFELD S, MADERA M, KONFORTOV B A, RIVERO F, BANKIER A T, LEHMANN R, HAMLIN N, DAVIES R, GAUDET P, FEY P, PILCHER K, CHEN G, SAUNDERS D, SODERGREN E, DAVIS P, KERHORNOU A, NIE X, HALL N, ANJARD C, HEMPHILL L, BASON N, FARBROTHER P, DESANY B, JUST E, MORIOT, ROSTR, CHURCHER C, COOPER J, HAYDOCKS, VAN DRIESSCHE N, CRONIN A, GOODHEAD I, MUZNY D, MOURIER T, PAIN A, LU M, HARPER 
D, LINDSAY R, HAUSER H, JAMES K, QUILES M, MADAN BABU M, SAITO T, BUCHRIESER C, WARDROPER A, FELDER M, THANGAVELU M, JOHNSON D, KNIGHTS A, LOULSEGED H, MUNGALL K, OLIVER K, PRICE C, QUAIL MA, URUSHIHARA H, HERNANDEZ J, RABBINOWITSCH E, STEFFEN D, SANDERS M, MA J, KOHARA Y, SHARP S, SIMMONDS M, SPIEGLER S, TIVEY A, SUGANO S, WHITE B, WALKER D, WOODWARD J, WINCKLER T, TANAKA Y, SHAULSKY G, SCHLEICHER M, WEINSTOCK G, ROSENTHAL A, COX E C, CHISHOLM R L, GIBBS R, LOOMIS W F, PLATZER M, KAY R R, WILLIAMS J, DEAR P H, NOEGEL A A, BARRELL B, KUSPA A (2005). The genome of the social amoeba Dictyostelium discoideum. Nature 435: 43-57.

ESCALANTE R, WESSELS D, SOLL D R, LOOMIS W F (1997). Chemotaxis to cAMP and slug migration in Dictyostelium both depend on MigA, a BTB protein. Mol Biol Cell 8: 1763-1775.

FOSNAUGH K, FULLER D, LOOMIS W F (1994). Structural roles of the spore coat proteins in Dictyostelium discoideum. Dev Biol 166: 823-825.

FOSNAUGH K L, LOOMIS W F (1993). Enhancer regions responsible for temporal and cell-type-specific expression of a spore coat gene in Dictyostelium. Dev Biol 157: 38-48.

FREE S J, LOOMIS W F (1974). Isolation of mutations in Dictyostelium discoideum affecting alpha-mannosidase. Biochimie 56: 1525-1528.

GOMER R H, YUEN I S, FIRTEL R A (1991). A secreted 80×103Mr protein mediates sensing of cell density and the onset of development in Dictyostelium. Development 112: 269-278.

GRABELL, LOOMIS W F (1978). Effector controlling accumulation of $\mathrm{N}$-acteylglucosaminidase during development of Dictyostelium discoideum. Dev Bio/64:203-209.

HECHT I, SKOGE M L, CHAREST P G, BEN-JACOB E, FIRTEL R A, LOOMIS W F, LEVINE H, RAPPEL W J (2011). Activated membrane patches guide chemotactic cell motility. PLoS Comput Biol 7: e1002044.

HIROSES, SANTHANAMB, KATOH-KUROSAWAM, SHAULSKY G, KUSPAA(2015) Allorecognition, via TgrB1 and TgrC1, mediates the transition from unicellularity to multicellularity in the social amoeba Dictyostelium discoideum. Development 142: 3561-3570.

HOPPER NA, SANDERS GM, FOSNAUGH KL, WILLIAMS JG, LOOMIS W $F$ (1995). Protein kinase $A$ is a positive regulator of spore coat gene transcription in Dictyostelium. Differentiation 58: 183-188.

INSALLR, KUSPAA, LILLYPJ, SHAULSKYG, LEVINLR, LOOMISWF, DEVREOTES $P$ (1994). CRAC, a cytosolic protein containing a pleckstrin homology domain, is required for receptor and $G$ protein-mediated activation of adenylyl cyclase in Dictyostelium. J Cell Biol 126: 1537-1545.

KUSPA A, LOOMIS W F (1992). Tagging developmental genes in Dictyostelium by restriction enzyme-mediated integration of plasmid DNA. Proc Natl Acad Sci USA 89: 8803-8807.

KUSPAA, LOOMIS W F (1994). REMI-RFLP mapping in the Dictyostelium genome. Genetics 138: 665-674.

KUSPAA, LOOMISWF (1996). Ordered yeast artificial chromosome clones representing the Dictyostelium discoideum genome. Proc Nat/Acad SciUSA 93: 5562-5566.

KUSPAA, MAGHAKIAN D, BERGESCH P, LOOMIS WF (1992). Physical mapping of genes to specific chromosomes in Dictyostelium discoideum. Genomics 13: 49-61.

LAUB M T, LOOMIS W F (1998). A molecular network that produces spontaneous oscillations in excitable cells of Dictyostelium. Mol Biol Cell 9: 3521-3532.

LEVINE H, ARANSON I, TSIMRING L, TRUONG T V (1996). Positive genetic feedback governs cAMP spiral wave formation in Dictyostelium. Proc Natl Acad Sci USA 93: 6382-6386.

LOOMIS W, DIMOND R, FREE S, WHITE S (1977). Independent and dependent sequences in development of Dictyostelium. In: O'Day DH, Horgen PA (eds.) Eukaryotic microbes as model developmental systems. Dekker, New York, pp 177-193.

LOOMIS W, SUSSMAN M (1966). Commitment to the synthesis of a specific enzyme during cellular slime mold development. $J$ Mol Biol 22: 401-404.

LOOMIS W F (1969) Temperature-sensitive mutants of Dictyostelium discoideum. $J$ Bacteriol 99: 65-69.

LOOMIS W F (1975). Dictyostelium discoideum. A developmental system. Acad Press, New York

LOOMIS W F (Ed.) (1982). The development of Dictyostelium discoideum. Ac. Press, New York

LOOMIS W F (1988). Four billion years: an essay on the evolution of genes and organisms. Sinauer Associates, Sunderland, MA.

LOOMIS W F (2016a). A better way to discover gene function in the social amoeba Dictyostelium discoideum. Genome Res 26: 1161-1164.

LOOMIS W F (2016b). My Life with Dicty. dictybase.org

LOOMIS W F CANN R (1982). Bibliography on Dictyostelium. In: Loomis W F (Ed.) The development of Dictyostelium discoideum. Ac. Press, New York, pp 451-538.

LOOMIS W F, FULLER D, GUTIERREZ E, GROISMAN A, RAPPEL W J (2012). Innate non-specific cell substratum adhesion. PLoS One 7: e42033.

LOOMIS W F, GILPIN M E (1986). Multigene families and vestigial sequences. Proc Natl Acad Sci USA 83: 2143-2147.

LOOMIS W F JR., MAGASANIK B (1965). Genetic control of catabolite repression of the lac operon in Escherichia coli. Biochem Biophys Res Commun 20: 230-234.

LOOMIS WF, JR, MAGASANIKB (1966). Nature of the effector of catabolite repression of beta-galactosidase in Escherichia coli. J Bacteriol 92: 170-177.

LOOMIS WF, JR, MAGASANIK B (1967). The catabolite repression gene of the lac operon in Escherichia coli. J Mol Biol 23: 487-494.

LOOMIS W F, KUSPA A (Eds.) (2005). Dictyostelium Genomics. Horizon Scientific Press, Norfolk, UK.

LOOMIS W F, LOOMIS W F JR. (1960). Constancy of the $\mathrm{pCO}_{2}$ in the ocean. Biol. Bull. 119: 295-296.

LOOMIS W F, SHAULSKY G (2011). Developmental changes in transcriptional profiles. Dev. Growth Diff. 53: 567-575.

LOOMIS W F, SMITH D W (1990). Molecular phylogeny of Dictyostelium discoideum by protein sequence comparison. Proc Natl Acad Sci USA 87: 9093-9097.

LOOMIS W F, SMITH D W (1995). Consensus phylogeny of Dictyostelium. Experientia 51: 1110-1115

LOOMIS W F, WELKER D, HUGHES J, MAGHAKIAN D, KUSPAA (1995). Integrated maps of the chromosomes in Dictyostelium discoideum. Genetics 141: 147-157.

LOOMIS W F, WHITE S, DIMOND R L (1976). A sequence of dependent stages in the development of Dictyostelium discoideum. Dev Biol 53:171-177.

LOSICK R, PERO J (1976). Bacillus subtilis RNA polymerase and its modification in sporulating and phage-infected bacteria. Adv Enzymol Relat Areas Mol Biol 44:165-185

MAEDA M, LU S J, SHAULSKY G, MIYAZAKI Y, KUWAYAMA H, TANAKA Y, KUSPA A, LOOMIS W F (2004). Periodic signaling controlled by an oscillatory circuit that includes protein kinases ERK2 and PKA. Science 304: 875-878.

MAEDAM, SAKAMOTO H, IRANFARN, FULLERD, MARUOT, OGIHARAS, MORIO T, URUSHIHARA H, TANAKA Y, LOOMIS W F (2003). Changing patterns of gene expression in Dictyostelium prestalk cell subtypes recognized by in situ hybridization with genes from microarray analyses. Euk Cell 2: 627-637.

MCCARROLL R, OLSON G J, STAHL X D, WOESE C R, SOGIN M L (1983) Nucleotide sequence of the Dictyostelium discoideum small-subunit ribosomal ribonucleic acid inferred from the gene sequence: evolutionary implications. Biochem 22: 5858-5868.

MORRISSEY J H, LOOMIS W F (1981). Parasexual genetic analysis of cell proportioning mutants of Dictyostelium discoideum. Genetics 99: 183-196.

NELLEN W, SILAN C, FIRTEL R A (1984). DNA-mediated transformation in Dictyostelium discoideum: regulated expression of an actin gene fusion. Mol Cell Biol 4: $2890-2898$

NELLEN W, SILAN C, SAUR U, FIRTEL R A (1986). Regulatory sequences in the promoter of the Dictyostelium actin 6 gene. EMBO J 5: 3367-3372.

NICOL A, RAPPEL W J, LEVINE H, LOOMIS W F (1999). Cell-sorting in aggregates of Dictyostelium discoideum. J Cell Sci 112: 3923-3929.

NUCKOLLS G H, OSHEROV N, LOOMIS W F, SPUDICH J A (1996). The Dictyostelium dual-specificity kinase $s p / A$ is essential for spore differentiation. Development 122:3295-3305.

OSHEROV N, WANG N, LOOMIS W F (1997). Precocious sporulation and developmental lethality in yelA null mutants of Dictyostelium. Dev Genet 20: 307-319.

PARENT C A, DEVREOTES P N (1999). A cell's sense of direction. Science 284 765-770.

PARIKH A, MIRANDA E R, KATOH-KURASAWA M, FULLER D, ROT G, ZAGAR L, CURK T, SUCGANG R, CHEN R, ZUPAN B, LOOMIS W F, KUSPAA, SHAULSKY $G$ (2010). Conserved developmental transcriptomes in evolutionarily divergent 
species. Genome Biol 11: R35.

RAPPEL W J, NICOL A, SARKISSIAN A, LEVINE H, LOOMIS W F (1999). Selforganized vortex state in two-dimensional Dictyostelium dynamics. Phys Rev Lett 83: 1247-1250.

ROSENGARTEN RD, SANTHANAM B, FULLER D, KATOH-KURASAWA M, LOOMIS WF, ZUPAN B, SHAULSKY G (2015). Leaps and lulls in the developmental transcriptome of Dictyostelium discoideum. BMC Genomics 16: 294.

SCHIESTL R H, PETES T D (1991) Integration of DNA fragments by illegitimate recombination in Saccharomyces cerevisiae. Proc Nat/Acad SciUSA 88: 7585-7589.

SEGALL JE, KUSPA A, SHAULSKY G, ECKE M, MAEDA M, GASKINS C, FIRTEL RA, LOOMIS WF (1995) AMAP kinase necessary for receptor-mediated activation of adenylyl cyclase in Dictyostelium. J Cell Biol 128: 405-413.

SHAULSKY G, ESCALANTE R, LOOMIS W F (1996). Developmental signal transduction pathways uncovered by genetic suppressors. Proc Natl Acad Sci USA 93: 15260-15265.

SHAULSKY G, KUSPA A, LOOMIS W F (1995). A multidrug resistance transporter serine protease gene is required for prestalk specialization in Dictyostelium. Genes Devel 9: 1111-1122.

SKOGE M, YUE H, ERICKSTAD M, BAE A, LEVINE H, GROISMAN A, LOOMIS W F, RAPPEL W J (2014). Cellular memory in eukaryotic chemotaxis. Proc Natl Acad Sci USA 111: 14448-14453.

SONG J, XU Q, OLSEN R, LOOMIS W F, SHAULSKY G, KUSPA A, SUCGANG R (2005). Comparing the Dictyosteliumand Entamoebagenomes reveals an ancient split in the Conosa lineage. PLoS Comput Biol 1: e71.
STEGE J T, SHAULSKY G, LOOMIS W F (1997). Sorting of the initial cell types in Dictyostelium is dependent on the tipA gene. Dev Biol 185: 34-41.

SUSSMAN M, OSBORN M J (1964). UDP-galactose polysaccharide transferase in the cellular slime mold Dictyostelium discoideum: appearance and disappearance of activity during cell differentiation. Proc Natl Acad Sci USA 52: 81-87.

SUSSMAN R, LOOMIS W, ASHWORTH J, SUSSMAN M (1967). The effect of actinomycin D on cellular slime mold morphogenesis. Biochem Biophys Res Commun 26: 353-359.

TARANTOLA M, BAE A, FULLER D, BODENSCHATZ E, RAPPEL W J, LOOMIS W F (2014). Cell substratum adhesion during early development of Dictyostelium discoideum. PLoS One 9: e106574.

WANG N, SHAULSKY G, ESCALANTE R, LOOMIS W F (1996). A two-component histidine kinase gene that functions in Dictyostelium development. EMBO J 15: 3890-3898.

WANG N, SODERBOM F, ANJARD C, SHAULSKY G, LOOMIS WF (1999). SDF-2 induction of terminal differentiation in Dictyostelium discoideum is mediated by the membrane-spanning sensor kinase DhkA. Mol Cell Biol 19: 4750-4756.

WESSELS D J, ZHANG H, REYNOLDS J, DANIELS K, HEID P, LU S J, KUSPA A, SHAULSKY G, LOOMIS W F, SOLL D R (2000). The internal phosphodiesterase RegA is essential for the suppression of lateral pseudopods during Dictyostelium chemotaxis. Mol Biol Cell 11: 2803-2820.

YANAGISAWA K, LOOMIS W F, SUSSMAN M (1967). Developmental regulation of the enzyme UDP-galactose polysaccharide transferase. Exp Cell Res 46:328-334. 


\section{Further Related Reading, published previously in the Int. J. Dev. Biol.}

Evidence for an evolutionary relationship between Vmp1 and bacterial DedA proteins Luis-Carlos Tábara, Olivier Vincent and Ricardo Escalante Int. J. Dev. Biol. (2019) 63: 67-71

https://doi.org/10.1387/ijdb.180312re

Dictyostelium discoideum Sir2D modulates cell-type specific gene expression and is involved in autophagy

Rakhee Lohia, Punita Jain, Mukul Jain, Pradeep Kumar Burma, Anju Shrivastava and Shweta Saran

Int. J. Dev. Biol. (2017) 61: 95-104

https://doi.org/10.1387/ijdb.160038ss

The Dictyostelium prestalk inducer DIF-1 directs phosphorylation of a bZIP transcription factor

Yoko Yamada, Yuzuru Kubohara, Haruhisa Kikuchi, Yoshiteru Oshima, Hong-Yu Wang, Susan Ross and Jeffrey G. Williams Int. J. Dev. Biol. (2013) 57: 375-381

https://doi.org/10.1387/ijdb.130046jw

An orthologue of the Myelin-gene Regulatory Transcription Factor regulates Dictyostelium prestalk differentiation

Hiroshi Senoo, Hong-Yu Wang, Tsuyoshi Araki, Jeffrey G. Williams and Masashi Fukuzawa Int. J. Dev. Biol. (2012) 56: 325-334

https://doi.org/10.1387/ijdb.120030jw

Bimodal distribution of motility and cell fate in Dictyostelium discoideum

Pavana Goury-Sistla, Vidyanand Nanjundiah and Gopal Pande

Int. J. Dev. Biol. (2012) 56: 263-272

https://doi.org/10.1387/ijdb.113384ps

ASET/MYND chromatin re-modelling protein regulates Dictyostelium prespore patterning Beatriz Nuñez-Corcuera, Joanna Birch and Jeffrey G. Williams

Int. J. Dev. Biol. (2011) 55: 205-208

https://doi.org/10.1387/ijdb.113309bn

Synergy between two transcription factors directs gene expression in Dictyostelium tip-organiser cells

Hong Yu Wang and Jeffrey G. Williams

Int. J. Dev. Biol. (2010) 54: 1301-1307

https://doi.org/10.1387/ijdb.103141hw

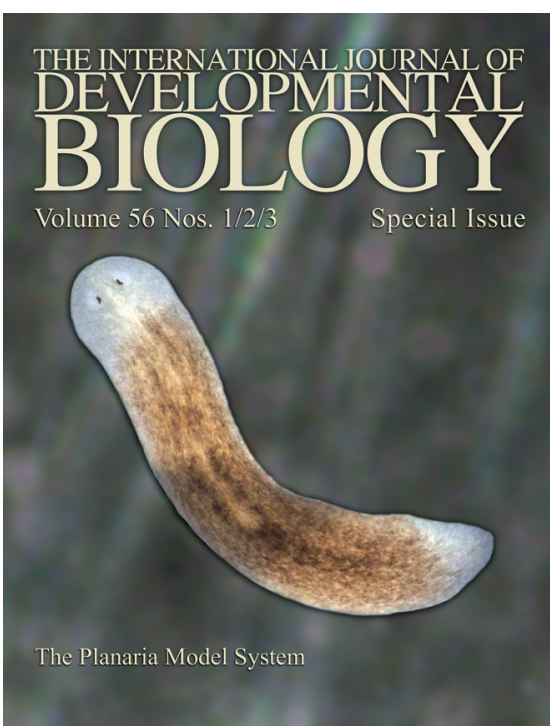

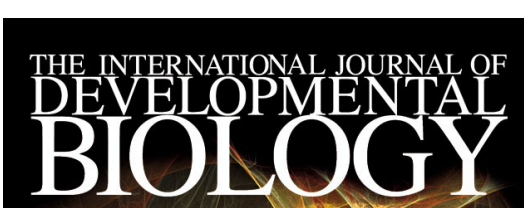

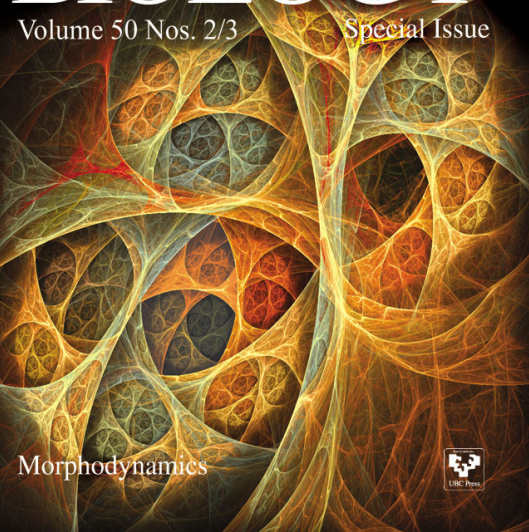

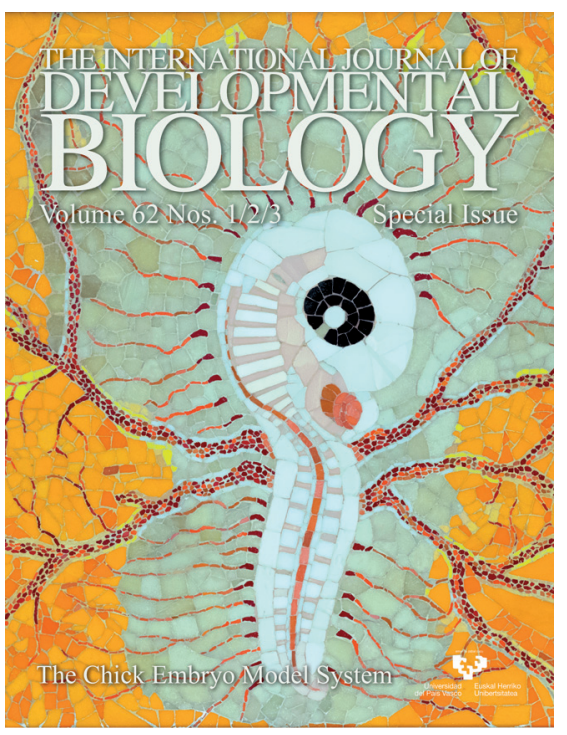
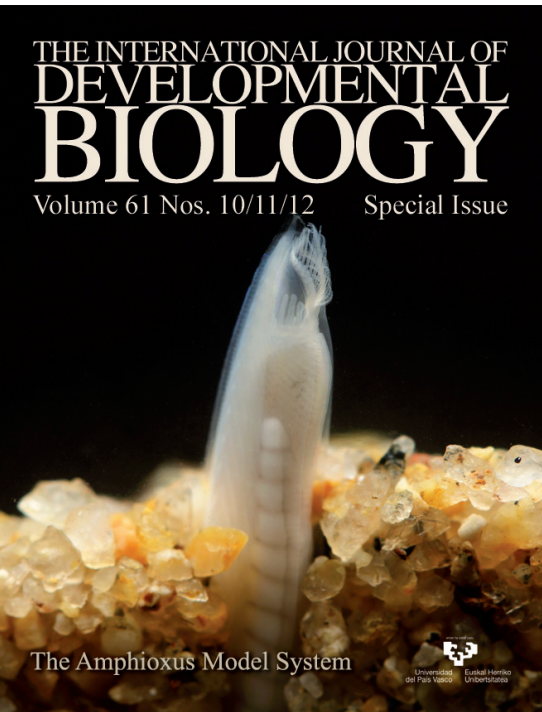